DOI: 10.2478/linpo-2014-0014

\title{
Learner perceptions of gender representation in EFL grammar books
}

\author{
Marcin Lewandowski \\ Institute of Linguistics, Adam Mickiewicz University \\ al. Niepodległości 4, 61-874 Poznań, marcinl@amu.edu.pl
}

\begin{abstract}
Marcin Lewandowski. Learner perceptions of gender representation in EFL grammar books. The Poznan Society for the Advancement of the Arts and Sciences. PL ISSN 0079-4740, ISBN 978-83-7654-388-8, pp. 61-72

It seems that there are very few research themes in sociolinguistics that have been as thoroughly explored as gender representation in educational materials (notably in EFL textbooks). However, relatively little attention has been paid to how learners themselves perceive the images of men and women in teaching resources. The present contribution has been written in an attempt to fill this gap. Drawing on the findings of two small-scale survey studies conducted among Polish university students, it addresses two major issues. The first one concerns the extent to which the choice of male or female-gendered sentence subjects in EFL grammar course books matches the learners' associations and expectations. The other one, focusing specifically on attitudes to gender representation, seeks to demonstrate how the students view the ways male and female characters are portrayed in constructed examples of usage and practice sentences from English grammar textbooks. Both studies provide some indications of how EFL learners' needs and expectations can be better addressed in teaching materials.
\end{abstract}

Keywords: language and gender, sexism, sexist language, gender stereotyping, gender representation in textbooks, EFL grammar books.

\section{Introduction}

The problem of gender depiction in educational materials (primarily in school textbooks) has attracted increasing interest since the 1970s, when the first influential studies of linguistic sexism in teaching resources were published (cf., e.g., U'Ren 1971; O'Donnell 1973; Nilsen 1977; Cincotta 1978; Hartman \& Judd 1978). The stereotyped and unfair portrayal of women and men was then addressed in an impressive amount of follow-up research ${ }^{1}$. According to Sunderland (1994: 55-56) ${ }^{2}$, gender stereotyping in textbooks can be found on the following six dimensions:

1 Cf. Motschenbacher (2012) for his list of recent studies of language, gender and sexuality.

2 Elsewhere, the researcher argues that gender role stereotyping in course books is more pervasive than in society at large (Sunderland 1992: 85). 
1. Invisibility - female characters are (sometimes statistically significantly) outnumbered by males.

2. Occupational stereotyping - men are shown as employed in a wider range of occupations than women. Males also happen to work in more prestigious jobs than females.

3. Relationship stereotyping - women are more frequently defined in relation to men than vice versa and more often depicted in domestic settings.

4. Personal characteristic stereotyping - related to sex-trait stereotypes (cf. Williams $\&$ Best 1990). For example, in educational materials, female characters are portrayed as emotionally unstable and overly emotional whereas males tend to be stereotyped as goaloriented, independent, and rational thinking individuals.

5. Disempowering discourse roles for female characters - women speak less than men (especially in public settings); when they do speak, their opinions tend to be ignored and dismissed.

6. Degradation - probably the most blatant form of sexism: women are made worthless and intellectually inferior to men more than the other way round (e.g. when they are the butt of jokes).

However, as many researchers have argued (cf., e.g., Jones et al. 1997; Sunderland et al. 2000; Yang 2011), the turn of the millennium and the following years saw a growing number of educational materials which in varying degrees managed to combat gender stereotyping on all of the above dimensions. In an earlier paper (Lewandowski 2014), I studied the representation of gender in UK-published EFL (English as a Foreign Language) grammar course books for advanced learners from a diachronic perspective. I demonstrated that in recent textbooks men and women are portrayed more fairly and in a less stereotyped manner than in the books that were first published in the 1970s and 1980s.

A number of analysts agree that gender stereotyping in educational resources may have a negative impact on learners (especially female ones). ${ }^{3}$ For example, Sunderland (1992: 86) maintains that EFL materials, by reinforcing gender-stereotyped traits and roles, can affect female learners in three ways: 1) they can aggravate the disempowerment of women; 2) they can make female students feel alienated and demotivated (and thus hamper their performance in the classroom), and 3) the patterns of language contained in them can become classroom routines. ${ }^{4}$ These views are largely shared by Macaulay \& Brice (1997: 820-821), who claim that sex stereotyping may be harmful to the effect that in the case of female learners, it can reduce their life options and cause discomfort or anger. As Harashima (2005: 1007) argues, "it may be more difficult for them [female students], compared to male students, to empathize with the characters in the textbook, therefore their motivation to study may be diminished". It is important to bear in mind that "no language $[\ldots]$ is ever produced in a social vacuum, as even the grammatical structures commonly practiced in the EFL classroom are almost always peopled with individuals who are recognizably men or women" (Pawelczyk et al. 2014: 50-51). However, there is very little evidence for how

3 This view, according to Amalsaleh et al. (2010: 2052), is in line with the Critical Discourse Analysis framework, which sees language as a powerful constitutive tool for disseminating ideologies and shaping viewpoints (cf., e.g., Fairclough 1993; van Dijk 2006).

4 However, in other contributions (Sunderland et al. 2000; Pawelczyk et al. 2014), she and other researchers emphasize that this negative impact can be significantly reduced by the instructor; more specifically, by the way they mediate course book texts. 
students themselves view the issue of gender representation in educational materials (and whether or not it is of any interest to them). ${ }^{5}$

Hence, it seems worthwhile investigating whether and how the images of men and women in EFL grammar books fit learners' expectations about gender traits and roles. In terms of their generic structure, these teaching resources, which cater for non-native users of English, are divided into units or chapters, each of which addresses a specific lexicogrammatical problem (examples include verb tenses, modal verbs, various clause types, article usage, word formation, idioms, words that are commonly confused or misused, etc.). A typical unit/chapter opens with explanations giving an overview of a particular problem (the commentary is illustrated with examples of usage). The latter part is designed to provide practice: it contains a series of exercises in various formats (e.g. sentence transformations, error analysis, gap-fill and multiple choice tests) aimed specifically at the point(s) covered in the chapter.

Of equal interest is also how learners perceive gender representation in these teaching materials; in other words, what is their attitude to constructed examples of usage and practice sentences containing male- and female-gendered sentence subjects? Are there any differences in these respects between older and recently published materials? Finally, is the sex of learners an important variable? In order to gain preliminary insights into these questions, two small-scale case studies have been conducted.

\section{Case study 1}

\subsection{Objectives and method}

In terms of semantic content both constructed examples and sentences from follow-up exercises in grammar textbooks are designed to appeal to learners' common knowledge, beliefs and attitudes, which are - in varying degrees - affected by stereotyping. Hence, I argue that grammar book writers, when selecting the grammatical gender for sentence subjects, may often relate to such stereotypical associations.

The first case study was designed to check to what extent EFL grammar textbook sentences match students' associations and expectations regarding gendered subjects. To this purpose, from the 6 EFL grammar books used in my previous study on gender representation (Lewandowski 2014) a total of 50 sentences were extracted. The sentences were chosen to represent 11 semantic domains delineated in the study, such as appearance, character traits, emotional states, employment, etc. Each sentence contained either a male or a female-gendered subject. The following is the list of the textbook titles with abbreviations for further reference.

1. Bywater, Frank V. 1971. A proficiency course in English. London: University of London Press - TB1

2. Thomson, Audrey J. \& Martinet, Agnes W. 1983. A practical English grammar. Oxford: Oxford University Press - TB2

3. Graver, Brian D. 1986. Advanced English practice. Oxford: Oxford University Press - TB3

4. Hewings, Martin. 2001. Advanced grammar in use: a self-study reference and practice book for advanced learners of English: with answers. Cambridge: Cambridge University Press - TB4

5 One such exception is Kizılaslan's (2010) study of the perception of gender representation conducted among teacher students in Turkey. It revealed a small degree of awareness of gender-stereotyped roles and traits in English language textbooks. 
5. Vince, Michael \& Sunderland, Peter. 2003. Advanced language practice with key: English grammar and vocabulary. Oxford: Macmillan Education - TB5

6. Foley, Mark \& Hall, Diane. 2008. Longman advanced learners'grammar: a self-study reference \& practice book with answers. Harlow: Longman - TB6

As can be seen by the dates of publication, the first three course books date from the 1970 s and 1980s, i.e. before the emergence of movements promoting non-sexist usage (inclusive language) in educational materials ${ }^{6}$, whereas the other three titles were published relatively recently, in the 2000s. For the sake of convenience, the first three textbooks will be referred to as the 'old textbooks' subcorpus (OTs), TB4-TB6 as the 'new textbooks' subcorpus (NTs). It was hypothesized that the NT writers were more likely to challenge gender stereotypes by assigning less traditional traits and roles to male and female characters in example and practice sentences. Thus, in order to corroborate this hypothesis, the 50-sentence corpus was designed to include an equal number of examples from the OTs and NTs (25 from each subcorpus).

The next step was a survey conducted among 60 undergraduate students ( 30 females, 30 males) from several degree programs at the Institute of Linguistics, Adam Mickiewicz University in Poznan. They were all enrolled in advanced EFL courses. The students were asked to complete a written questionnaire that contained the 50 corpus sentences from which gendered subjects had been removed. They were instructed to write in the missing sentence subjects based on whether they associated a particular trait, role, action or behavior with men or women, i.e. they were asked to insert sentence subjects that would match their own expectations. The students were told to use any pronouns or nouns provided that the selected forms were explicitly marked for masculine or feminine gender.

\subsection{Findings}

The study found a great degree of overlap between the textbook writers' choice of gendered subjects (male or female) and the students' expectations and associations regarding the grammatical gender of sentence subjects. The average predictability rate for all corpus sentences totaled $70 \%$, exceeding the chance level by $20 \%$. In raw figures, in seven out of ten sentences the gender of the grammatical subject was correctly anticipated by the respondents. However, at the same time the missing gendered subjects were easier to predict in the OT subcorpus (with a mean predictability rate of 78\%) than in the NT subset (62\%). What follows is the list of sentences with the highest subject predictability rates (provided in parentheses) with gendered subjects boldfaced:

Ann will be shopping (98\%) - TB2

Jim has just started work as an electrical engineer (98\%) - TB5

She sat up all night with the sick child (97\%) - TB2

Although he was drunk, he insisted on driving (95\%) - TB2

She was very much upset when she heard about your accident (95\%) - TB2

She was so upset that she couldn't help crying (93\%) - TB3

${ }^{6}$ A notable example is a set of guidelines published by the Linguistic Society of America (Linguistic Society of America 1996). See Lewandowski (2014: 85-86) for fuller discussion of this topic. 
Five of the above sentences are from the OT corpus and only one from a recent textbook. Through grammatical subject choice, they all reinforce gender stereotypical images. Examples 1 and 3 depict women as involved in 'traditionally female' chores, i.e. shopping and childcare. In sentences 5 and 6, a great number of the respondents opted for femalegendered subjects as women are stereotypically associated with such emotions and character traits as: distress, apprehension, and concern for others (allegedly, they are also more prone to tears). As regards the male subjects in the above examples, sentence 2 (the only one from the NT corpus) casts a male character in an occupational role conventionally ascribed to men rather than women while sentence 4 strengthens the stereotype of an intoxicated male driver. In view of the above (and given the overall subject predictability rate for the OT corpus), it can be argued that constructed sentences in older grammar course books tend to evolve around the roles and traits traditionally attributed to either sex and dwell on commonly shared associations.

The following sentences scored the lowest subject predictability rates:

$$
\text { She is answerable for the money that has disappeared (5\%)-TB4 }
$$

Jane stopped to check the oil level in the engine (7\%) - TB5

He does his homework conscientiously (13\%) - TB1

Jane was headhunted by a multinational company (15\%) - TB5

David broke down and wept when he heard the news (18\%) - TB5

She must have played really well to win. I wish I'd seen the match (22\%) - TB4

In the above set, a reverse pattern applies: five sentences come from the NT corpus, and only one from the OT corpus. Four examples show female characters in roles or domains that seem to be conventionally attributed to the opposite sex. Women seem to be (far) less frequently than men associated with such topics as: money issues, car maintenance, higher status jobs or sports competitions. Hence, most of the respondents expressed preference for male-gendered subjects in sentences 7, 8, 10 and 12 (the actual sentence subjects used in the course books are feminine). By contrast, men are not typically shown as suffering emotional breakdowns, which is why most of the survey participants opted for a female subject in sentence 11 (as they did in sentence 6 from the OT corpus, which is semantically similar). It appears then that the recent textbooks are more likely to challenge the existing stereotypes and, in some cases, confound the learners' expectations regarding gendered subjects. The choice of a male-gendered subject in example 9, the only sentence from the OT corpus in this set, should be viewed in terms of overall preference for male-gendered subjects ${ }^{7}$ in old EFL materials rather than as an attempt to defy gender stereotypes.

The study also sought to investigate whether male and female learners differ in their preferences for gendered subject choice; in other words, the question was: is the sex of the respondents related to their decisions as to the grammatical gender of the missing subjects? Overall, the survey respondents showed a fair amount of consistency in their answers: in $58 \%$ of the cases ( 29 out of the 50 corpus sentences), the difference between women's and men's predictability rates did not exceed $10 \%$. The mean predictability rate for the female

7 In old grammar books, women are far less visible than men in the domain of intellectual activity, being outnumbered by a proportion of 1:7 (cf. Lewandowski 2014: 93). 
respondents was $66 \%$ while for the male ones $-74 \%$. The male learners were also found to be more unanimous in their preferences: if we consider only the men's answers, it turns out that six corpus sentences $(12 \%)$ scored $100 \%$ subject predictability rates. In the female pool this unanimity was found in only two sentences $(4 \%)$.

However, in several cases the male and female participants differed in their expectations and associations regarding gendered subjects. The following six sentences exhibited the greatest quantitative divergence here. The figures in parentheses indicate the difference in subject predictability rates between the males' and females' answers:

He was very independent, and would never ask for help $\left(50 \%{ }^{8}\right)-$ TB3

Davy took a year out to see the world and broaden his experience of life (43\%) - TB6

He succeeded by working hard (33\%) - TB1

When he has a problem to solve, he will work at it until he finds a solution $(33 \%)-\mathrm{TB} 3$

He was a person whom everyone regarded as trustworthy (33\%) - TB5

He has a highly developed sense of humour (30\%) - TB1

An interesting pattern applies here: all of the above sentences contain male-gendered subjects. The male respondents opted overwhelmingly for masculine forms in subject positions. By contrast, most of the female participants supplied female-gendered subjects. It could thus be speculated that these young females associate themselves strongly with such character traits as: independence, diligence, determination and dependability, which are viewed as predominantly masculine by young men. Future grammar textbook writers should take note of this finding.

It can be concluded that the constructed sentences in the old EFL grammar textbooks mirror commonly shared associations and stereotypes to a greater extent than those in recent publications, but that there is variation with reader-gender here.

\section{Case study 2}

\subsection{Objectives and method}

As indicated, despite the vast body of research on the depiction of men and women in educational materials (primarily EFL textbooks), relatively few insights have been offered into how their users, i.e. learners, view the problem of gender representation in these resources. For example, are students sensitive to how males and females are portrayed in these materials? Do they notice any gender imbalances or bias? Do they approve of the ways in which stereotyping is challenged? In an attempt to provide answers to these questions, the second study was designed to investigate how adult advanced learners of English perceive the issue of gender representation in grammar books.

8 For this sentence the percentage was computed by deducting the women's predictability rate (20\%) from the men's score $(70 \%)$. The same formula was applied in the remaining examples. 
The answers were obtained through another survey conducted among 60 students (30 females and 30 males) from several BA programs at the Institute of Linguistics at Adam Mickiewicz University. ${ }^{9}$ The study, which surveyed a different set of respondents than the previous one, consisted of two major parts. In the first one, the students were asked to answer three multiple-choice questions related to the grammatical gender of sentences in grammar books. In the second one, they were asked to evaluate 14 constructed examples and practice sentences from the six grammar course books listed in 2.1. As it turned out, three of the textbooks, i.e. TB1, TB2 and TB4, served as resource materials for many of the respondents in their EFL Grammar class (in the survey the students were also asked to list the course books they had used at university level).

\subsection{Findings}

The first part of the survey was designed to determine the degree of the students' general awareness of gendered language in EFL course books. The respondents' answers to each question will be presented in tables.

1. While doing grammar exercises do you pay attention to the grammatical gender (male or female) of the subjects in constructed examples and practice sentences?

\begin{tabular}{ccrr}
\hline Answer & Women & Men & \multicolumn{1}{c}{ Total } \\
\hline Often & $30 \%$ & $23.3 \%$ & $\mathbf{2 6 . 7 \%}$ \\
Sometimes & $30 \%$ & $30 \%$ & $\mathbf{3 0 \%}$ \\
Rarely & $30 \%$ & $23.3 \%$ & $\mathbf{2 6 . 7 \%}$ \\
Never & $10 \%$ & $23.3 \%$ & $\mathbf{1 6 . 7 \%}$ \\
\hline
\end{tabular}

It is hard to make any generalizations here: some students argue that they do take notice of gendered subjects in constructed examples while others say they do this infrequently, if at all. The male respondents appear to be less attentive to this problem than the females.

2. Given the choice between male- and female-gendered subjects in constructed examples and practice sentences, do you intuitively think that:

(a) the former significantly outnumber the latter;

(b) the former outnumber the latter;

(c) the latter significantly outnumber the former;

(d) the latter outnumber the former;

(e) there is a relative balance between the former and the latter?

\begin{tabular}{crrr}
\hline Answer & Women & \multicolumn{1}{c}{ Men } & \multicolumn{1}{c}{ Total } \\
\hline $\mathrm{a}$ & $6.7 \%$ & $0 \%$ & $\mathbf{3 . 3 \%}$ \\
$\mathrm{b}$ & $56.7 \%$ & $36.7 \%$ & $\mathbf{4 6 . 7 \%}$ \\
$\mathrm{c}$ & $0 \%$ & $0 \%$ & $\mathbf{0 \%}$ \\
$\mathrm{d}$ & $0 \%$ & $0 \%$ & $\mathbf{0 \%}$ \\
$\mathrm{e}$ & $36.7 \%$ & $63.3 \%$ & $\mathbf{5 0 \%}$ \\
\hline
\end{tabular}

9 I wish to thank Dr. Marta Mazurek (the Institute of Linguistics, Adam Mickiewicz University) for her invaluable feedback on the survey format and content. 
Two answers clearly predominate: the students think that either male subjects occur more commonly than female subjects or that there is a more or less equal proportion of male and female subjects. Interestingly, the former view was widely held by the female respondents, the latter by the male ones. Thus, the sex of the respondents is related to the way they perceive gender representation. None of the surveyed students said that feminine subjects outnumber masculine ones.

As demonstrated in another study (Lewandowski 2014: 87), male-gendered subjects are used about 3.5 times more frequently than female-gendered ones in the old textbooks. In the recent course books, these proportions are far more balanced as men and women are almost equally represented (although male subjects are employed a little more frequently, outnumbering female subjects by 5.6\%). In view of the fact that most of the respondents are familiar with the textbooks from both subcorpora (as they use them in class), it seems that they demonstrated a good awareness of the quantitative representation of female and male characters in EFL grammar books.

3. Do you happen to make similar sentences to the ones you find in EFL grammar course books (e.g. when you are trying to explain grammar problems to other people)?

\begin{tabular}{ccrr}
\hline Answer & Women & \multicolumn{1}{c}{ Men } & \multicolumn{1}{c}{ Total } \\
\hline Often & $20 \%$ & $13.3 \%$ & $\mathbf{1 6 . 7 \%}$ \\
Sometimes & $60 \%$ & $60 \%$ & $\mathbf{6 0 \%}$ \\
Rarely & $20 \%$ & $23.3 \%$ & $\mathbf{2 1 . 7 \%}$ \\
Never & $0 \%$ & $3.3 \%$ & $\mathbf{1 . 7 \%}$ \\
\hline
\end{tabular}

This question was designed to check whether the structure and the semantic content of grammar textbook sentences are related to actual language use. As it turns out, most of the male and female respondents (almost in the same proportion) say they use similar examples to the ones they find in the EFL grammar books. Even if this happens infrequently, as the above data indicate, this would mean that learners may transfer and reinforce at least some of the stereotypical views that constructed examples and practice sentences contain.

In the second part of the survey the students were asked to provide their opinions on 14 sentences containing male- and female-gendered subjects. All sentences had been carefully selected: half had been taken from TB1-TB3 (the OT corpus), the other half from TB4-TB6 (the NT corpus). In most of the sentences, the female and male characters in subject positions were assigned what is believed to be gender-stereotypical traits, behaviors and roles (the amount of stereotyping varied from examples bordering on blatant sexism to less obvious cases of stereotyping). However, within the 14-sentence corpus there were also examples that challenged existing gender stereotypes, sometimes by casting male and female characters in mold-breaking roles. The students were expected to provide feedback on all of the sentences by indicating the answer(s) (they could choose more than one) that came closest to their views. They were offered the following six options:

(a) the sentence sounds offensive to women/men;

(b) the sentence reflects the stereotypical perception of gender roles and traits;

(c) the sentence sounds natural (i.e. is free from gender stereotyping);

(d) the sentence sounds artificial/unnatural/strange; 
(e) the sentence challenges the stereotypical perception of gender roles and traits;

(f) the sentence is difficult to evaluate.

The following is an overview of the most important quantitative and qualitative findings.

Overall, the most frequently selected option was answer (c) $-47.1 \%$. On average, to every respondent, nearly half of the sentences were free from gender stereotyping. The following three examples scored highest on naturalness:

She is just as beautiful as I imagined - TB6.

John offered me a lot of money for the car-TB5.

A girl was playing the piano and singing softly - TB2.

In teaching materials, women are much more frequently than men defined by appearance (especially by physical attractiveness) and predilection for music whereas males are more often than females associated with cars (cf. Macaulay \& Brice 1997: 810-811). However, more than $75 \%$ of the respondents did not perceive the above sentences as containing gender-stereotypical views.

This does not mean though that the surveyed students failed to recognize gender stereotyping in the 14-sentence corpus. The second most common option was answer (b) $-27.5 \%$. The respondents varied in their assessment of the constructed examples (a small proportion viewed sentences 19-21 as gender-stereotyped). Below are two sentences that were rated by over $60 \%$ of the survey participants as mirroring the stereotypical perception of gender roles and traits:

Women are expected to like housework-TB2.

Surely the husband has the right to make the decisions since it is he who pays the bills - TB2.

These sentences sound demeaning to women and show them as inferior to men. No wonder then that these examples of blatant sexism were viewed by many respondents as offensive. Option (a) was indicated by $35 \%$ of the respondents in example 22 , and by $40 \%$ - in example 23.

The overall selection rate for option (e) was $11.5 \%$. The following three sentences, all of which come from the same textbook, were evaluated by approximately half of the surveyed students as defying existing stereotypes:

The escaped prisoner couldn't find anywhere to hide so she gave herself up TB5.

Jane stopped to check the oil level in the engine - TB5.

David broke down and cried when he heard the news - TB5.

Sentences 25 and 26 have already been discussed in the previous section. Interestingly, when evaluating these two examples, a number of respondents selected option (c) (40\% and $36.7 \%$, respectively). It follows then that some learners appear to perceive stereotype-challenging examples as natural-sounding. However, sentence 24 was judged less favorably: $46.7 \%$ of the survey participants said that it is artificial/unnatural/strange (option e) compared to barely $16.7 \%$ who claimed that it sounds natural. This may indicate that learners 
do not necessarily approve of all the mold-breaking roles that male or female characters are cast in (a female runaway prisoner clearly confounds their expectations and preferences).

In general, the sentences were similarly evaluated by the female and male respondents: option (c) was almost equally selected by the male (48.8\%) and female (45.5\%) students. However, sex did prove to be an important variable. The female participants were more prone to assess some of the sentences as containing either gender-stereotyped or gender offensive views ${ }^{10}$. The males were more inclined to describe the very same examples as natural-sounding. By contrast, the men were twice as likely as the women to judge some sentences as unnatural/strange/artificial (e.g. sentences 24-26). In such cases, the female students selected either option (c) or (e).

Overall, the sentences from the new textbooks were found to be much more frequently described as challenging prevailing stereotypes than the OT examples $(22.6 \%$ vs. $0.5 \%)$. The latter, in turn, scored significantly higher on options (a) and (b) with overall selection rates of $12.6 \%$ and $34.3 \%$, respectively as compared to $1.9 \%$ and $20.7 \%$ for the NT sentences. This is yet another indicator that recent EFL grammar course books depict both women and men (and boys and girls) in more balanced and less stereotypical ways than their predecessors.

\section{Conclusions}

The first of the two studies showed that EFL grammar textbook sentences, in terms of gendered subject choice, largely fit learners' expectations regarding images of gender. In the construction of example and practice sentences, however, the authors of new course books rely on less obvious or conventional associations about gender roles, traits, and behaviors. As the survey in the first case study demonstrated, the subject predictability rate for sentences in the new textbooks was 16\% lower than for the old textbooks. Example and practice sentences in the recently published materials depict male and female characters in a less gender-stereotypical manner.

The second survey revealed a moderate degree of gender awareness among learners. The respondents do not ignore the problem of gender representation in grammar textbooks. They largely disapprove of sentences which sound offensive to either sex (primarily to women) or contain overtly sexist attitudes. In other words, they are strongly opposed to what Sunderland (1994) and others call degradation. On the other hand, however, the survey respondents do not seem to be strongly opposed to milder or more subliminal forms of stereotyping present in some sentences (such examples are often judged as natural-sounding). Nor are they critical of stereotype-challenging sentences. It seems that the students view such sentences favorably provided that they are somehow grounded in reality. While stereotypes do need to be defied, I would argue that this should not be done by putting male or female characters in highly unlikely or untypical roles.

Judging by the responses to both surveys, the young women seem to be more sensitive to and aware of the issues of gender imbalance and stereotyping. As the first survey showed,

10 Overall, option (a) was selected by the females over $40 \%$ more frequently than by the males $(8.6 \%$ vs. $6 \%$ ). Option (b) accounted for $29.2 \%$ of all female responses compared to $25.8 \%$ of the male ones. 
they favor a stronger presence of females with such character traits as: independence, determination and diligence. The female respondents also sound more critical of the sentences containing sexist and gender-stereotyped views. By contrast, the male students are more disapproving of stereotype-defying sentences.

Last but not least, it would be unreasonable to deny the view that the content of textbooks has no effect on the way their users perceive the world through language. The scope of this impact may vary significantly among learners, judging by the responses to question 3 in the second survey. Needless to say, if positive change in gender representation is to continue, writers and editors need to be fully aware that the linguistic content of their course books will have implications on the way at least some of their users will think and communicate.

The present paper attempts to provide only basic insights into how learners perceive gender representation in EFL grammar textbooks. Clearly, there is a need for more in-depth similar studies of other genres of language teaching materials (e.g. integrated-skills textbooks). Their findings would be central to a better understanding of the needs of foreign language learners and to an up-to-date gender representation.

\section{References}

Amalsaleh, Ehya \& Javid, Fatemeh \& Rahimi, Ali. 2010. The power of language and ELT textbooks. Procedia Social and Behavioral Sciences 9. 2052-2056.

Cincotta, Madeleine Strong. 1978. Textbooks and their influence on sex-role stereotype formation. Babel: Journal of the Australian Federation of Modern Language Teacher's Association 14(3). 24-29.

Fairclough, Norman. 1993. Discourse and social change. Cambridge: Polity Press.

Harashima, Hideto D. 2005. Sexual bias in an EFL textbook: A case study. In Bradford-Watts, Kim \& Ikeguchi, Cecilia \& Swanson, Malcolm (eds.), JALT2004 Conference Proceedings, 1005-1011. Tokyo: JAL.

Hartman, Pat L. \& Judd, Elliot L. 1978. Sexism and TESOL Materials. TESOL Quarterly 12(4). 383-393.

Jones, Martha A. \& Kitetu, Catherine \& Sunderland, Jane (1997). Discourse roles, gender and language textbook dialogues: Who learns what from John and Sally? Gender and Education 9(4). 469-490.

Kizılaslan, Irem. 2010. Student teachers' perceptions of gendered texts in English language textbooks. Procedia Social and Behavioral Sciences 2. 3528-3531.

Lewandowski, Marcin. 2014. Gender stereotyping in EFL grammar textbooks. A diachronic approach. Linguistik Online 68(6). 83-99.

Linguistic Society of America.1996. LSA Bulletin. December.

Macaulay, Monica \& Brice, Colleen. 1997. Don't touch my projectile: Gender bias and stereotyping in syntactic examples. Language 73(4). 798-825.

Motschenbacher, Heiko. 2012. An interdisciplinary bibliography on language, gender and sexuality (2000-2011). Amsterdam: John Benjamins Publishing Company.

Nilsen, Alleen Pace. 1977. Sexism in children's books and elementary classroom materials. In Nilsen, Alleen Pace \& Bosmajian, Haig \& Gershuny, H. Lee \& Stanley, Julia P. (eds.), Sexism and language, 161-179. Urbana, Illinois: National Council of Teachers of English.

O’Donnell, Richard W. 1973. Sex Bias in Primary Social Studies Textbooks. Educational Leadership 31. 137-141.

Pawelczyk, Joanna \& Pakuła, Łukasz \& Sunderland, Jane. 2014. Issues of power in relation to gender and sexuality in the EFL classroom: An overview. Journal of Gender and Power 1. 49-66.

Sunderland, Jane. 1992. Gender in the EFL classroom. ELT Journal 46(1). 81-90.

Sunderland, Jane. 1994. Introduction to Quadrant II. In Sunderland, Jane (ed.), Exploring gender: Questions and implications for English language education, 55-66. New York: Prentice Hall.

Sunderland, Jane \& Cowley, Maire \& Abdul Rahim, Fauziah Abdul \& Leontzakou, Christina \& Shattuck, Julie. 2000. From bias "in the text" to "teacher talk around the text": An exploration of teacher discourse and gendered foreign language textbook texts. Linguistics and Education 11. 251-286. 
U'Ren, Marjorie B. 1971. The image of woman in textbooks. In Gornick, Vivian \& Moran, Barbara K. (eds.), Woman in sexist society: Studies in power and powerlessness, 218-225. New York: Basic Books.

van Dijk, Teun A. 2006. Ideology and discourse analysis. Journal of Political Ideologies 11(2). 115-140.

Williams, John E. \& Best, Deborah L. 1990. Measuring Sex Stereotypes: A Multination Study. Newbury Park, CA: Sage Publications.

Yang, Chi Cheung Ruby. 2011. Gender representation in a Hong Kong primary English textbook series: The relationship between language planning and social policy. Current Issues in Language Planning 12(1). 77-88. 